\title{
Motivational Effect of Web-Based Simulation Game in Teaching Operations Management
}

\author{
Tung Nhu Nguyen \\ Correspondence: Tung Nhu Nguyen, International University-Vietnam National University Ho Chi Minh City, Viet \\ Nam
}

Received: October 27, 2014 Accepted: November 13, 2014 Online Published: January 26, 2015

doi:10.11114/jets.v3i2.565

URL: http://dx.doi.org/10.11114/jets.v3i2.565

\begin{abstract}
Motivational effects during a simulated educational game should be studied because a general concern of lecturers is motivating students and increasing their knowledge. Given advances in internet technology, traditional short in-class games are being substituted with long web-based games. To maximize the benefits of web-based simulation games, a game should instill intrinsic motivation in students and encourage them to adopt deep-learning strategies. We have conducted a quasi-experimental study of 53 students, divided into game and no-game groups, as part of an operations management course. During the course, the game group played a web-based simulation game lasting 7 days; the no-game group did not play this game at all. The findings revealed that students who played the game experienced a deeper level of learning. However, students who did not play the game felt more competent and exerted greater efforts. These results are useful for challenging the assumed benefits of educational games at motivating students. Furthermore, our findings open up opportunities for finding more factors that affect the motivation and behavior of individual students.
\end{abstract}

Keywords: intrinsic motivation, deep learning, effort, simulation game, operations management

\section{Introduction}

\subsection{Web-Based Simulated Game in Teaching Operations Management}

In general, simulations are the "art and science of creating a representation of a process or system for the purpose of experimentation and evaluation" (Gogg \& Mott, 1993). In educational institutions, simulations are designed in the form of games to combine education with leisure. Simulation games in teaching operations management adopt a problem-based learning (PBL) approach (Kanet, 2007; Naik, 2011). The PBL approach requires lecturers in operations management to introduce students to real-world business operations problems that need to be diagnosed and solved. Simulation games are composed of a model or "an abstraction of an economic environment" and a simulation that is "the series of rules for manipulation of the model" and a game or "a set of rules which govern the activity of the participants in relation to the simulation" (McKenney \& Dill, 1966). "Web-based simulation represents the connection between the web and the field of simulation" (Fishwick, 1996). Internet technology is bringing real business into classrooms via web-based games, which stimulate the active engagement of students to diagnose problems in particular contexts, analyze provided information, and formulate an implementation plan. We use a web-based simulation game called Littlefield Laboratories developed by the Responsive Learning Technologies Company based in the United States. The game, designed in the form of a goal-based scenario, "allows students to systematically refine their understanding and intuition of system behavior through exploration and iterative experimentation" (Responsive Learning Technologies).

The game aims to maximize the cash balance for Littlefield Lab, which provides blood-testing services using a four-step process (Fig. 1). Students assemble into teams and spend exactly 7 days, equivalent to 268 simulated days, operating the lab by accessing a team account on the internet. The winning team will have the largest cash balance in the end of the simulation term. The game is designed in a highly-integrative manner in which teams have to diagnose problems related to demand forecasting, capacity planning, inventory lot sizing, reorder point level determination, and sequencing. The students have to prepare a plan to address problems. When the game is over, the students will complete a report that assesses their plan. A lecturer or a tutor simply plays a facilitating role during the game. This educational game offered as pilot innovative part of operations management syllabus for business undergraduate students in the School of 
Business - International University - Vietnam National University from 2012 to 2014.

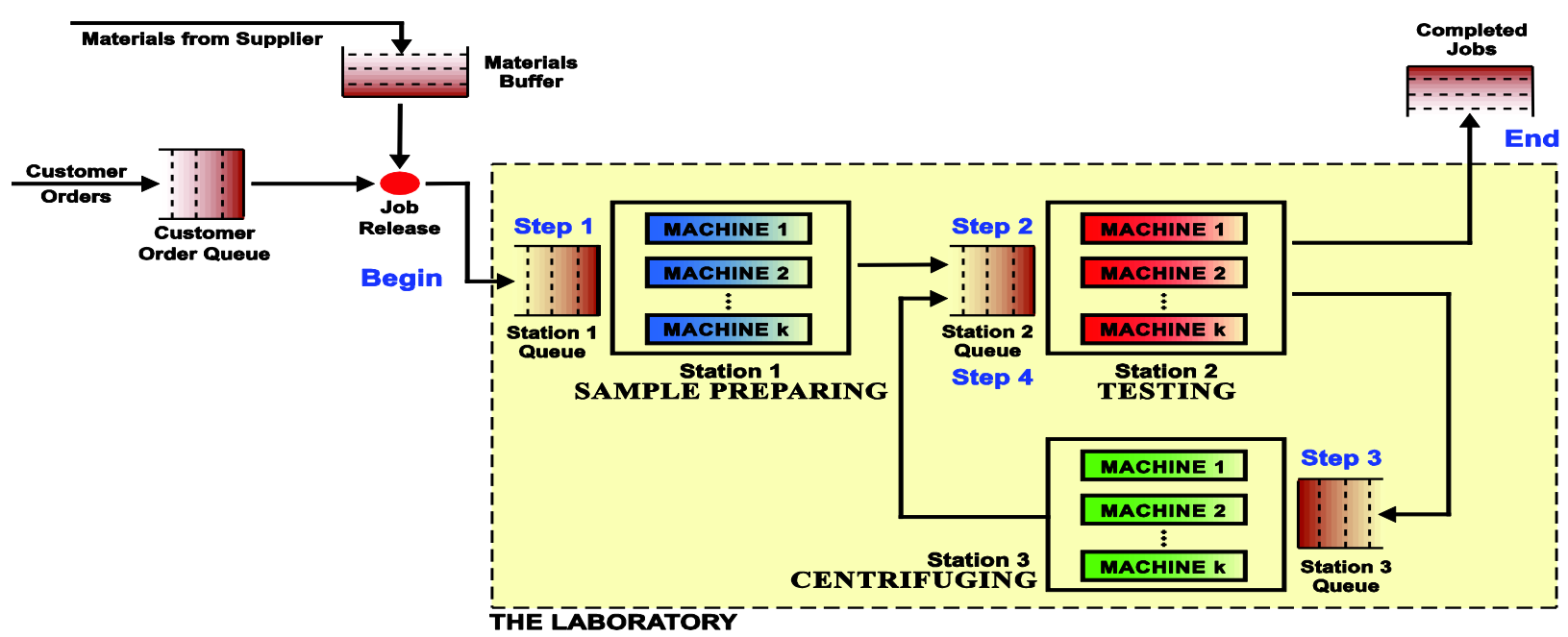

Figure 1. Production Process of the Littlefield Laboratories (Source: Responsive Learning Technologies)

\subsection{Study Objective}

The objective of the study is to assess the impact of the web-based simulated game practiced in operations management courses on students' intrinsic motivation and their use of deep learning strategy at university level in Vietnam. This impact is also compared to that of no-game conventional teaching approach. The findings of the study will confirm or reject the benefits of this game in generating positive study behavior, i.e. high motivation, hence the game could be proposed as official part supplement to the current syllabus or a more suitable game design could be recommended for motivating students.

\subsection{Significance of the Study}

The web-based simulated game for operations management used for this study was for the first time applied in a university in Vietnam, as confirmed by the game provider Reponsive Learning Technologies Co. To assess its impact on the degree of student-perceived benefits is very necessary because the assessment results of this pilot innovative can be used to justify future investments made by the researcher's university in this educational game and serve as a pilot demonstration for other Vietnam's universities and institutes to adopt or adapt. The focus of this evaluation is motivational effect because it is believed that highly-motivated students would be more likely to be engaged in the learning process.

\subsection{Relevant Literature}

\subsubsection{The Impact of Gaming on Students' Intrinsic Motivation}

The intrinsic motivation of a person stems from his or her feelings of competency, personal development, and self-control experience in his or her work, which arises from within (Ryan \& Deci, 2000). Many empirical studies have found that games enhance student motivation, including competence, interest or curiosity, and efforts (Burguillo, 2010; Cordova \& Lepper, 1996; Tuzun, Yilmaz-Sollu, Karakus, Inal, \& Kizilkaya, 2008). Vos Meijden Denessen (2011) found that the students who learned in the game-based learning environment demonstrated statistically significantly higher levels of intrinsic motivation than those who learned in a traditional school environment.

\subsubsection{The Impact of Gaming on Deep Learning Strategy Use and Achievement}

An educational game should aim to have its players adopt deeper learning strategies. During the game, players are forced to confront specific problems that they must overcome if they wish to achieve the goal of the game. Students accordingly have to develop deep learning strategies rather than just surface learning (Biggs, 1993; Vos Meijden Denessen, 2011). Surface-learning students who just memorize information have difficulty solving the hard problems of the game; it is necessary to analyze information by "linking it to already known concepts and principles, and leads to long-term retention of concepts (i.e. longer memory) so that they can be used for problem-solving in unfamiliar contexts" (Vos Meijden Denessen, 2011). Game-based learning can be an effective learning environment for increasing students' levels of deep learning, by critical thinking, problem-solving, decision-making, knowledge transfer and meta-analytic skills (Gee, 2003; Kirriemuir \& MacFarlane, 2004; Wideman et al., 2007).

\subsubsection{Problem-Based Learning (PBL) in Web-Based Simulation Games in Operations Management}


The difference in teaching methodologies between traditional and PBL approaches is highlighted by the statement that "the traditional approach centers on lectures given by well-trained teachers who are expert in the field, while the PBL approach is based on small groups of students working on tasks under the guidance of a well-trained tutor who is not necessarily an expert in the field to be studied" (Keizer, 1995). The PBL approach challenges teams of students to work together to solve business problems. The role of the instructor is to facilitate the students (Kanet, 2007). The "experiential PBL orientation" and simulation game will ensure a "competition" among teams and serve as a motivation for learning. Nadik et al. (2011) used a supply chain game developed by Responsive Learning Technologies Co., in an operations management course, and assessed students' perceptions of their attitudes toward the game. This web-based simulation game adopts the PBL approach by integrating requirements for decision making on strategic, tactical, and operational levels in supply chain management. Decision topics include demand forecasting, location, lot sizing, reorder point, and capacity planning, among others. The findings of a post-game survey revealed that half or more of the responding students agreed or strongly agreed that the game increased their skills for forecasting, making decisions in inventory planning, working as a team member, and making group decisions. In addition, $72 \%$ of students perceived that playing the game required more time and effort compared with similar activities in other courses.

Nevertheless, some studies showed conflicting results about the effects of web-based simulation games. A study conducted by IBM revealed that after a game on the internet "most participants did not express interest in websites that involved active interaction with the content or other people" and that the "users interacted relatively infrequently with the [online] tours, and the less they interacted, the more they reported feeling engaged and entertained by the experience." (Karat et al., 2001). These findings mean that students may be more interested in passive learning than in a highly collaborative team game. Since the Littlefield Lab simulation game is a team game on the internet, played for the first time at an English-speaking university in Vietnam, it is necessary to evaluate the game's impact on the students' learning process. The objectives of this study - to assess motivational effects - address that intention.

\section{Method}

\subsection{Research Design}

The experiment as conducted quantitatively at the School of Business - International University - Vietnam National University in Ho Chi Minh City, Vietnam. The game-learning condition was conducted in summer 2014 and the no-game condition was offered in spring 2014. A total of 53 students in game and no-game learning conditions responded to an online survey questionnaire. For the game condition, an operations management course taught in summer 2014 employed a web-based simulation game designed by Responsive Learning Technologies Co. The students were sent an email with a link to an online survey form after they had completed 7 days of playing the game. Twenty-nine students completed the survey form. The no-game group, after completing the operations management course in spring 2014, did not play the web-based simulation game. Instead, they were assigned problem textbooks and in-class exercises. A total of 24 students in the no-game group answered the online survey questionnaire.

\subsection{Instruments}

A 5-point Likert scale was used to measure intrinsic motivation and deep learning strategy use ( $1=$ strongly disagree; 2 = disagree; $3=$ neutral; $4=$ agree; $5=$ strongly agree). The survey question items were adopted from the motivation model of Vos et al. (2011). Intrinsic motivation is composed of three dimensions: competence (4 items), interest in study (4 items), and efforts (4 items). Deep-learning strategy use is composed of 4 items.

\subsection{Data Collection and Analysis Process}

After the no-game group finished their operations management course, they were asked to complete the online survey form. For the game group, game teams had one week for playing the game and one week for their final report preparation. In the second week, team members were sent an email with a link to the online survey. The data analysis process included a reliability scale test and analysis of covariance.

\section{Results}

\subsection{Descriptive Statistics}

\subsubsection{Perceived Judgment on Motivation and Deep-Learning Strategy during the Game}

Table 1 lists perceived intrinsic motivation during the game. On the one hand, less than a half of the students agreed or strongly agreed that the game produced competence and interest. On the other hand, some students disagreed or strongly disagreed with that fact. Concretely, $24.1-37.9 \%$ disagreed or strongly disagreed that the game made them competent and $13.8 \%$ disagreed that playing the game was quite enjoyable. In terms of efforts, the students' perceptions on the motivational effects of the game were more positive. More than a half of the students $(51.7 \%)$ agreed or strongly agreed that the game made them do their best. Only maximum $13.8 \%$ of students did not perceive that they exerted 
significant effort during the game. In general, more students believed that the game forced them try their best than the number of students who disagreed with that fact. In terms of deep-learning strategy use, Table 1 showed that the students perceived that playing the game they adopted deeper learning strategy. Concretely, 41.4-55.2\% of students agreed or strongly agreed that the game made them study more thoroughly; 6.9-37.9\% of students disagreed or strongly disagreed with that fact.

Table 1. Students' perceptions on post-game competence, interest, effort and deep-learning strategy use

\begin{tabular}{|c|c|c|c|c|c|}
\hline Construct & $\begin{array}{c}\text { Strongly } \\
\text { disagree } \\
(\%)\end{array}$ & $\begin{array}{c}\text { Disagree } \\
(\%)\end{array}$ & $\begin{array}{c}\text { Neutral } \\
(\%)\end{array}$ & $\begin{array}{c}\text { Agree } \\
(\%)\end{array}$ & $\begin{array}{c}\text { Strongly } \\
\text { agree } \\
(\%)\end{array}$ \\
\hline \multicolumn{6}{|l|}{ Competence (Cronbach's alpha $=0.902)$} \\
\hline F1. I think I was good at playing the game & 10.3 & 27.6 & 27.6 & 27.6 & 6.9 \\
\hline F2. I think I did pretty well at playing the game, compared to others & 6.9 & 31.0 & 24.1 & 31.0 & 6.9 \\
\hline F3. I am satisfied with my performance at playing the game & 0.0 & 24.1 & 41.4 & 34.5 & 0.0 \\
\hline F4. I am pretty skilled at playing the game & 10.3 & 20.7 & 37.9 & 20.7 & 10.3 \\
\hline \multicolumn{6}{|l|}{ Interest (Cronbach's alpha $=0.864)$} \\
\hline G1. I think playing the game was quite enjoyable & & 13.8 & 44.8 & 31.0 & 10.3 \\
\hline G2. I think playing the game was very interesting & 3.4 & 10.3 & 44.8 & 17.2 & 24.1 \\
\hline $\begin{array}{l}\text { G3. While I was playing the game I often thought about how much I } \\
\text { enjoyed it }\end{array}$ & 3.4 & 10.3 & 41.4 & 27.6 & 17.2 \\
\hline G4. I think playing the game was boring & 10.3 & 48.3 & 20.7 & 17.2 & 3.4 \\
\hline \multicolumn{6}{|l|}{ Effort (Cronbach's alpha $=0.857)$} \\
\hline H1. I did my best while I was playing the game & 3.4 & 10.3 & 34.5 & 27.6 & 24.1 \\
\hline H2. I tried very hard to well play the game. & 3.4 & 3.4 & 51.7 & 27.6 & 13.8 \\
\hline H3. It was important to me to play well the game & 3.4 & 6.9 & 37.9 & 41.4 & 6.9 \\
\hline H4. I put much effort in playing the game. & & 13.8 & 41.4 & 27.6 & 17.2 \\
\hline \multicolumn{6}{|l|}{$\begin{array}{l}\text { Deep-learning Strategy Use } \\
\text { (Cronbach's alpha }=0.784 \text { ) }\end{array}$} \\
\hline $\begin{array}{l}\text { I1. I found playing this game interesting and want to spend extra time } \\
\text { trying to play more games }\end{array}$ & 13.8 & 6.9 & 41.4 & 27.6 & 10.3 \\
\hline $\begin{array}{l}\text { I2. While playing this game, I asked myself questions to check whether } \\
\text { I understood the problems of the game assignment. }\end{array}$ & & 6.9 & 37.9 & 41.4 & 13.8 \\
\hline I3. I want to spend free time playing these kinds of games & 10.3 & 27.6 & 20.7 & 27.6 & 13.8 \\
\hline I4. I thought playing this game was instructive & & 13.8 & 41.4 & 37.9 & 6.9 \\
\hline
\end{tabular}

Note: The purpose of the question item G4 ("I think playing the game was boring.") is to check the response reliability or consistency. When processed in SPSS software, the values of this variable were reversed to be consistent with other measures in the group of interest (i.e., 1 becomes 5; 2 becomes 4). The reliability test results showed that all of the constructs are reliable (Cronbach's alpha >0.7).

\subsubsection{Compared Mean Scores between Game and No-Game Conditions}

Table 2. Comparison of group mean scores for game and no-game conditions

\begin{tabular}{llcccc}
\hline & & \multicolumn{2}{c}{ No-game Condition } & \multicolumn{2}{c}{ Game Condition } \\
& & Mean & SD & Mean & SD \\
\hline Competence & Male & 3.3889 & 0.9109 & 3.2500 & 1.1180 \\
& Female & 3.4667 & 0.4364 & 2.8529 & 0.8797 \\
\hline Interest & Male & 3.0000 & 0.6614 & 3.2500 & 1.0113 \\
& Female & 3.3333 & 0.4479 & 3.5588 & 0.7475 \\
\hline Effort & Male & 3.5000 & 0.6614 & 3.4167 & 0.7638 \\
& Female & 3.6833 & 0.4479 & 3.4168 & 0.9880 \\
\hline Deep learning strategy use & Male & 3.1389 & 0.7512 & 3.2083 & 0.9405 \\
& Female & 2.9833 & 0.3467 & 3.4706 & 0.8380 \\
\hline
\end{tabular}

Table 2 shows that the average competence score of the game group was lower than that of the no-game group for both males and females $(3.39>3.25 ; 3.47>2.85)$. However, the average interest score of the game group was higher than that of no-game group for both sexes, showing that the learning environment integrated with the game is more interesting $(3.00<3.25 ; 3.33<3.55)$. The average effort score of the game group was lower than that of the no-game group for both sexes $(3.50>3.41 ; 3.68>3.41)$. Lastly, we noted that the mean score of the deep-learning strategy use in the game group was better that that of the no-game group for both sexes $(3.13<3.20 ; 2.98<3.47)$, indicating that the game assignment was challenging enough to require the game players to concentrate deeply on their study, as opposed to simply completing textbook problems. 


\subsubsection{Correlation between Pre-Game and Post-Game Scales}

The pre-game question items measure the students' general intrinsic motivation and deep-learning strategy use, based on their previous schooling experience; the post-game question items measure the students' specific intrinsic motivation and deep-learning strategy use, based on the game or no-game condition. To test the measurement stability of the questionnaire used, we calculated Pearson's correlations. The correlation calculations showed that post-game competence, effort, and deep-learning strategy use were significantly correlated with pre-game competence, effort, and deep-learning strategy use (competence $r=0.52, \mathrm{p}<0.01$; effort $\mathrm{r}=0.45, \mathrm{p}<0.01$; strategy $\mathrm{r}=0.59, \mathrm{p}<0.01$ ). Only the "interest" measure did not show a significant correlation before and after the game $(r=0.22, p>0.01)$. The correlations showed that there was consistency in motivation and strategy use in students. In other words, if a student is motivated in his studies in general, he will also be motivated during the game. The next analysis of covariance was to test the significance of the impact of the pre-game motivation scales and strategy use on the post-game motivation scales and strategy use.

\subsection{Analysis of Covariance}

In this experimental study, we assessed the effects of learning conditions (game and no-game) on student intrinsic motivation by comparing the average post-game intrinsic motivation score (competence, interest, effort) and the average post-game score of deep-learning strategy use in the two groups, controlling the effects of student pre-game motivation and strategy use. Analyses of covariance (ANCOVA) were performed with post-game motivation and strategy use scores as dependent variables and the pre-game scores as covariates.

\subsubsection{Impact of Learning Condition on Post-Game Deep-Learning Strategy Use}

Table 3 lists the ANCOVA with the post-game deep-learning strategy score as a dependent variable, the pre-game strategy score as a covariate, and the learning game condition as a factor. The ANCOVA results show a product of condition and pre-game strategy, $\mathrm{F}(1.123)=0.329>0.05$, meaning that there is no interaction effect between these two variables. Table 3 shows that there is a significant difference in mean scores for strategy use between the two condition groups $(\mathrm{p}=0.027<0.05)$. The higher mean score is in favor of game condition (Table 2$)$.

Table 3. ANCOVA Result for post-game deep-learning strategy use

\begin{tabular}{lllllll}
\hline Source & Type III Sum of Squares & df & Mean Square & F & Sig. & Partial Eta Squared \\
\hline Corrected Model & $10.601 \mathrm{a}$ & 2 & 5.300 & 18.068 & .000 & .420 \\
Intercept & .096 & 1 & .096 & .326 & .571 & .006 \\
Pre-game strategy & 9.713 & 1 & 9.713 & 33.108 & .000 & .398 \\
Condition & 1.525 & 1 & 1.525 & 5.200 & .027 & .094 \\
Error & 14.668 & 50 & .293 & & & \\
Total & 562.563 & 53 & & & & \\
Corrected Total & 25.269 & 52 & & & & \\
a. R Squared =.420 (Adjusted R Squared =.396) & & & & \\
\hline
\end{tabular}

\subsubsection{Impact of Learning Condition on Post-Game Motivation (Competence, Interest, Effort)}

Table 4 shows the ANCOVA with the post-game intrinsic motivation score as a dependent variable, the pre-game motivation score as a covariate, and the learning game condition as a factor. The pre-game competence and learning condition predict post-game competence (Table 4). However, with pre-game competence as a covariate, the product of pre-game competence and learning condition is also significant $(\mathrm{F}(5.620)=0.022<0.05)$, meaning that an interaction effect exists between these two variables. In "interest," there is no significant difference in mean scores between the two condition groups $(\mathrm{p}=0.179>0.05)$ and pre-game interest, the covariate does not influence the post-game interest $(\mathrm{p}=$ $0.070>0.05)$. In "effort," there is no significant difference in effort scores between the groups $(p=0.569>0.05)$ and ANCOVA revealed that the pre-game effort is significantly related to the post-game effort $(\mathrm{p}=0.001<0.05)$.

Table 4. ANCOVA for post-game intrinsic motivation

\begin{tabular}{|c|c|c|c|c|c|c|c|c|c|c|c|c|}
\hline Source & $\begin{array}{l}\text { post-game coml } \\
\text { Type III Sum } \\
\text { of Squares }\end{array}$ & eten & $\mathrm{F}$ & Sig. & $\begin{array}{l}\text { post-game inter } \\
\text { Type III Sum } \\
\text { of Squares }\end{array}$ & df & $\mathrm{F}$ & Sig. & $\begin{array}{l}\text { post-game effort } \\
\text { Type III Sum } \\
\text { of Squares }\end{array}$ & df & $\mathrm{F}$ & Sig. \\
\hline $\begin{array}{l}\text { Corrected } \\
\text { Model }\end{array}$ & $11.840 \mathrm{a}$ & 2 & 12.574 & .000 & $2.776 \mathrm{a}$ & 2 & 2.271 & .114 & $5.295 \mathrm{a}$ & 2 & 6.497 & .003 \\
\hline Intercept & 1.104 & 1 & 2.346 & .132 & 9.466 & 1 & 15.488 & .000 & 7.184 & 1 & 17.629 & .000 \\
\hline condition & 2.152 & 1 & 4.571 & .037 & 1.137 & 1 & 1.861 & .179 & .134 & 1 & .329 & .569 \\
\hline pre-game & 9.425 & 1 & 20.017 & .000 & 2.091 & 1 & 3.421 & .070 & 5.123 & 1 & 12.571 & .001 \\
\hline Error & 23.542 & 50 & & & 30.557 & 50 & & & 20.375 & 50 & & \\
\hline Total & 579.063 & 53 & & & 622.222 & 53 & & & 694.313 & 53 & & \\
\hline $\begin{array}{l}\text { Corrected } \\
\text { Total }\end{array}$ & 35.382 & 52 & & & 33.333 & 52 & & & 25.670 & 52 & & \\
\hline
\end{tabular}


a. $\mathrm{R}$ Squared $=.335$ (Adjusted R Squared $=.308$ )

\section{Discussion}

We used a quasi-experimental approach to examine the influence of a web-based simulation game, played in an operations management course, on student intrinsic motivation and use of deep-learning strategy. An ANCOVA technique was used to test the significance of this impact and the interaction effect between pre-game motivation and strategy use on learning conditions (game or no-game).

\subsection{Deep-Learning Strategy Use}

We found that playing the game forced the game group to study more thoroughly than the no-game group; this difference was significant. Interaction effect testing revealed that pre-game strategy use, as a covariate, is not significantly related to post-game strategy use. This fact is a positive point from the game because it is believed that deep learning contributes to longer retention of concepts.

\subsection{Intrinsic Motivation (Competence, Interest, Effort)}

There was no significant difference between the two condition groups in mean scores for interest and effort. The results challenged the assumed motivational advantages thought to result from the game method versus the traditional no-game method. More interestingly, the mean score in competence for the no-game group was better than that of the game group; this difference was significant.

These results surprisingly do not support the idea that the motivational effects of a game will have a positive impact on students. The students did not exert a significant effort playing the game, which may be due to several possible reasons. If students are not interested, they are not engaged and they will not exert an effort. It is also possible that the game/website design and game grading were not demanding enough to force the students to try their best. University-level students may furthermore be less interested in playing games than primary-level students. Additionally, students might not have felt competent at playing the game maybe because it could have been inconvenient or harder than just opening a textbook and doing written exercises. The learning style of each individual student may also contribute to our findings. An IBM evaluation found that students tend to be passive leisure game players, rather than frequently interacting with other team members (Karat et al., 2001). The game in this study is highly demanding in terms of team dynamics, which may explain why the students were not very interested or engaged.

There are also a number of further reasons that may explain our findings. First, a majority of the participants had not taken any quantitative courses, as confirmed in class. Since this simulation requires quantitative decision-making techniques such as forecasting and capital budgeting, students without this background may find the game particularly challenging. Second, most of the students were learning for the first time how to run a business based on maximizing profits; the majority of students were sophomores. If the game was run a second time, the students would likely perform much better. Third, since the game lasted only one week and the students played the game on their own time, the researcher could not monitor how often each of the students accessed the website to play the game. Finally, since the game represented teamwork, it is impossible to avoid social loafing, a phenomenon in which some students take advantage of the competence and efforts of other more enthusiastic students. This phenomenon may have led to the low levels of perceived competence and effort. Worse, if the keen and competent students recognized the free-riders, the more advanced students might have felt the lack of equity when all team members equally enjoyed the same team score.

\section{Conclusion}

The analysis results suggested that designing a web-based simulation for enriching operations management education should consider some issues such as game website attractiveness, access monitoring system, individual performance assessment. Assessment of team performance needs to be supplemented with member performance evaluation to ensure fairness in marking. The use of this simulation needs to be officially integrated in the operations management course syllabus for consistence over academic semesters. In addition, students registering operations management course should have prior knowledge on quantitative analysis so that they can apply quantitative techniques for making decisions in this simulation.

One limitation of this study is it relatively small number of participants (53). Qualitative research, with in-depth interview or focus group discussion, should be included in future studies to examine critical issues during the game. Games are believed to bring about motivational effects but this study did not provide evidence for this fact. For example, how much do good teamwork and dynamics influence team effectiveness? How does social loafing impact teamwork? Also, technological and psychological barriers need to be identified. We recommend that future research focus on the following issues. First, a Technology Acceptance Model should be used to explore factors affecting students' behavior to use the game website. Some factors, such as ease of use and perceived usefulness, are believed to be related to users' 
behavior to accept a technology product (or website in this case). Second, education researchers should investigate how passive learners are enjoying a game that requires a high level of teamwork. This research direction is important for educational contexts in Asia, where students traditionally experience passive learning approaches.

\section{References}

Biggs, J. (1993). What do inventories of students' learning processes really measure? A theoretical review and clarification. British Journal of Educational Psychology, 63(1), 3-19. http://dx.doi.org/10.1111/j.2044-8279.1993.tb01038.x

Burguillo, J. C. (2010). Using game theory and competition-based learning to stimulate student motivation and performance. Computers \& Education, 55(2), 566-575. http://dx.doi.org/10.1016/j.compedu.2010.02.018

Cordova, D. I., \& Lepper, M. R. (1996). Intrinsic motivation and the process of learning: Beneficial effects of contextualization, personalization, and choice. Journal of educational psychology,88(4), 715. http://dx.doi.org/10.1037/0022-0663.88.4.715

Fishwick, P. A. (1996). Web-based simulation: some personal observations. Paper presented at the Proceedings of the 28th conference on Winter simulation.

Gogg, T. J., \& Mott, J. R. A. (1993). Introduction to simulation. Proceedings of the 1993 Winter Simulation Conference, ed. G. W. Evans, M. Mollaghasemi, E. C. Russell, W. E. Biles. http://dx.doi.org/10.1109/WSC.1993.718023

Kanet, J. J. (2007). Problem-based Learning - Lessons Learned from an Undergraduate Operations Management Program. Paper presented at the POMS 18th annual conference, Dallas, Texas, USA.

Karat, C. M., Pinhanez, C., Karat, J., Arora, R., \& Vergo, J. (2001). Less clicking, more watching: results of the interactive design and evaluation of entertaining web experiences. In Proceedings of IFIP TC. 13 International Conference on Human - Computer Interaction. IOS Press, Amsterdam (pp. 455-463).

Keizer, P. K. PBL, Ideology Or Practical Solution?. Educational Innovation in Economics and Business Administration. Springer Netherlands, 1995. 53-61. http://dx.doi.org/10.1007/978-94-015-8545-3_6

Kirriemuir, J., \& McFarlane, A. (2004). Literature review in games and learning. http://dx.doi.org/10.1111/j.1541-0072.1974.tb01308.x

McKenney, J. L., \& Dill, W. R. (1966). Influences on learning in simulation games. American Behavioral Scientist, 10(2), 28-32. http://dx.doi.org/10.1177/000276426601000205

Naik, B. (2011). Using PBL Assignments in Undergraduate Operations Management Course. Journal of Higher Education THeory and Practice, 11(2), 84-90.

Ryan, R. M., \& Deci, E. L. (2000). Intrinsic and extrinsic motivations: Classic definitions and new directions. Contemporary educational psychology, 25(1), 54-67. http://dx.doi.org/10.1006/ceps.1999.1020

Tüzün, H., Yılmaz-Soylu, M., Karakuş, T., İnal, Y., \& Kızılkaya, G. (2009). The effects of computer games on primary school students' achievement and motivation in geography learning. Computers \& Education, 52(1), 68-77. http://dx.doi.org/10.1016/j.compedu.2008.06.008

Vos, N., Meijden, H., \& Denessen, E. (2011). Effects of constructing versus playing an educational game on student motivation and deep learning strategy use. Computers \& Education, 56(1), 127-137. http://dx.doi.org/10.1016/j.compedu.2010.08.013

Wideman, H. H., Owston, R. D., Brown, C., Kushniruk, A., Ho, F., \& Pitts, K. C. (2007). Unpacking the potential of educational gaming: A new tool for gaming research. Simulation \& Gaming,38(1), 10-30. http://dx.doi.org/10.1177/1046878106297650

\section{$(\mathrm{cc}) \mathrm{BY}$}

This work is licensed under a Creative Commons Attribution 3.0 License. 